\title{
Rancang Bangun Sistem Kontrol Penetas Telur Ayam Kampung Menggunakan Metode MADM dan SMS Gateway
}

\author{
Tijaniyah $^{1}$, Honainah ${ }^{2}$ \\ ${ }^{1}$ Teknik Elektro, Universitas Nurul Jadid Paiton Probolinggo, Indonesia \\ ${ }^{2}$ Teknik Informatika, Universitas Nurul Jadid Paiton Probolinggo, Indonesia \\ 1tijaniyah@unuja.ac.id, ${ }^{2 h o n a i n a h @ u n u j a . a c . i d ~}$
}

\begin{abstract}
Abstraks-Proses pengeraman telur yang baik merupakan faktor utama kualitas telur ayam kampung yang selama ini induk ayam kampung banyak mengalami kendala seperti sedikitnya telur yang menetas, banyaknya induk ayam yang tidak tahan cuaca sehingga banyak telur yang tidak menetas dan benih ayam dalam telur mati, sedikitnya indukan ayam yang mengerami telurnya, tidak adanya metode yang tepat dalam perhitungan parameter suhu dan kelembapan kandang ayam serta tidak adanya informasi proses penetasan telur kepada peternak secara realtime. Mengatasi persoalan tersebut, dibutuhkan teknologi terbaru yang dapat menggantikan sistem konvensional peternak dengan sistem terkontrol penetas telur ayam. Dalam hal ini, penulis akan membuat mesin yang dilengkapi dengan sistem kontrol penetasan telur ayam kampung menggunakan metode perhitungan MADM dan teknologi SMS Gateway sebagai media informasi kepada peternak.
\end{abstract}

Kata Kunci : Telur, Ayam, Mikrokontroler, MADM.

Abstract- The process of good egg incubation is a major factor in the quality of native chicken eggs which during this time the native chicken mother has many problems such as the lack of eggs that hatch, the number of chickens that are not weather resistant so many eggs that do not hatch and chicken seeds in dead eggs, at least chicken breeders which incubates the eggs, there is no proper method in calculating the temperature and humidity parameters of the chicken coop and there is no information on the process of hatching eggs to farmers in real time. Overcoming this problem, the latest technology is needed that can replace the conventional system of farmers with a controlled system of chicken egg incubators. In this case, the author will make a machine equipped with a chicken hatching control system using the MADM calculation method and SMS Gateway technology as a medium of information to farmers.

Keywords: Egg, Chicken, Microcontroller, MADM

\section{PENDAHULUAN}

Bidang Peternakan merupakan salah satu bidang yang banyak membantu perekonomian masyarakat dan menjadi target perkembangan teknologi. Salah satu usaha ternak yang memiliki nilai ekonomis tinggi adalah beternak ayam kampung [1]. Tingginya permintaan masyarakat akan daging ayam menjadi salah satu bakti usaha yang bernilai ekonomis tinggi dan daging ayam kampung yang sehat merupakan kebutuhan pokok masyarakat sehari - hari[2][3].

Proses pengeraman telur telur ayam yang baik adalah faktor utama kualitas telur [4]. Proses ini memiliki banyak usaha seperti pengeraman langsung dan tidak langsung yang di lakukan oleh induk ayam. Pengeraman tidak langsung menggunakan kecanggihan teknologi banyak di kembangkan agar peternak dapat menambah bibit ayam lebih banyak sehingga menghasilkan telur ayam yang lebih banyak. Penetasan telur ayam membutuhkan waktu selama kurang lebih 21 hari dengan suhu yang berbeda setiap minggunya[1][2]. Proses Pengeraman telur ayam dengan indukannya selama ini banyak mengalami kendala seperti sedikitnya telur menetas, banyaknya induk ayam tidak tahan cuaca sehingga banyak telur yang tidak menetas dan benih ayam dalam telur mati, sedikitnya indukan ayam yang mengerami telurnya sedangkan permintaan masyarakat akan kebutuhan pokok daging ayam sangat tinggi, tidak adanya metode yang tepat dalam perhitungan penelitian parameter suhu dan kelembapan kandang ayam pada waktu tertentu dimana selama ini masyarakat melakukannya secara konvensional. Serta tidak adanya informasi proses penetasan telur kepada peternak telur sehingga peternak tidak dapat mengetahui informasi secara realtime.

Mengatasi persoalan tersebut, dibutuhkan teknologi terbaru yang dapat menggantikan sistem konvensional peternak ayam dengan sistem terkontrol penetasan telur ayam dan metode perhitungan parameter suhu dan kelembapan kandang ayam secara tepat. Sehingga dalam proses penetasan telur ayam menjadi lebih mudah, praktis dan telur yang bernilai ekonomis tinggi. Penulis akan membuat sebuah sistem kontrol penetasan telur ayam menggunakan metode penghitungan MADM (Multi Attribute Decision Making) sehingga hasil penghitungan menjadi akurat dan tervalidasi. Metode MADM salah satu metode terbaik dalam menentukan beberapa parameter masalah menjadi sebuah hasil yang tepat [5].

Alat ini merupakan teknologi terbaru bagi peternak ayam. Alat ini menggunakan Mikrokontroler sebagai sistem kontrol suhu dan kelembapan kandang ayam. Selain menggunakan mikrokontroler, alat ini juga menggunakan Sistem SMS Gateway yang berfungsi untuk mengirim Informasi kepada peternak tentang proses penetasan telur seperti kondisi suhu dan masa penetasan telur ayam. Keunggulan lainnya adalah penggunaan aktuator untuk pemutaran untuk pemutaran rak telur dengan sudut $45^{\circ}$ sehingga penyampaian suhu dapat merata pada semua telur, selain itu dapat menampung sebanyak 50 butir telur ayam. Berdasarkan Paparan Latar belakang diatas, penulis akan mengembangkannya dalam sebuah penelitian yang berjudul 
"Rancang Bangun Sistem Kontrol Penetas Telur Ayam menggunakan Metode MADM dan Sms Gateway".

\section{METODE PENELITIAN}

\section{A. Metode Penelitian Waterfall}

Metode penelitian yang digunakan yaitu Metode Waterfall. Metode Waterfall merupakan suatu proses pengembangan perangkat lunak berurutan, di mana kemajuan dipandang sebagai terus mengalir ke bawah (seperti air terjun) melewati fase-fase perencanaan, pemodelan, implementasi (konstruksi) dan pengujian. Berikut ini adalah tahapan penelitian pada metode waterfall dapat dilihat pada Gambar 1 .

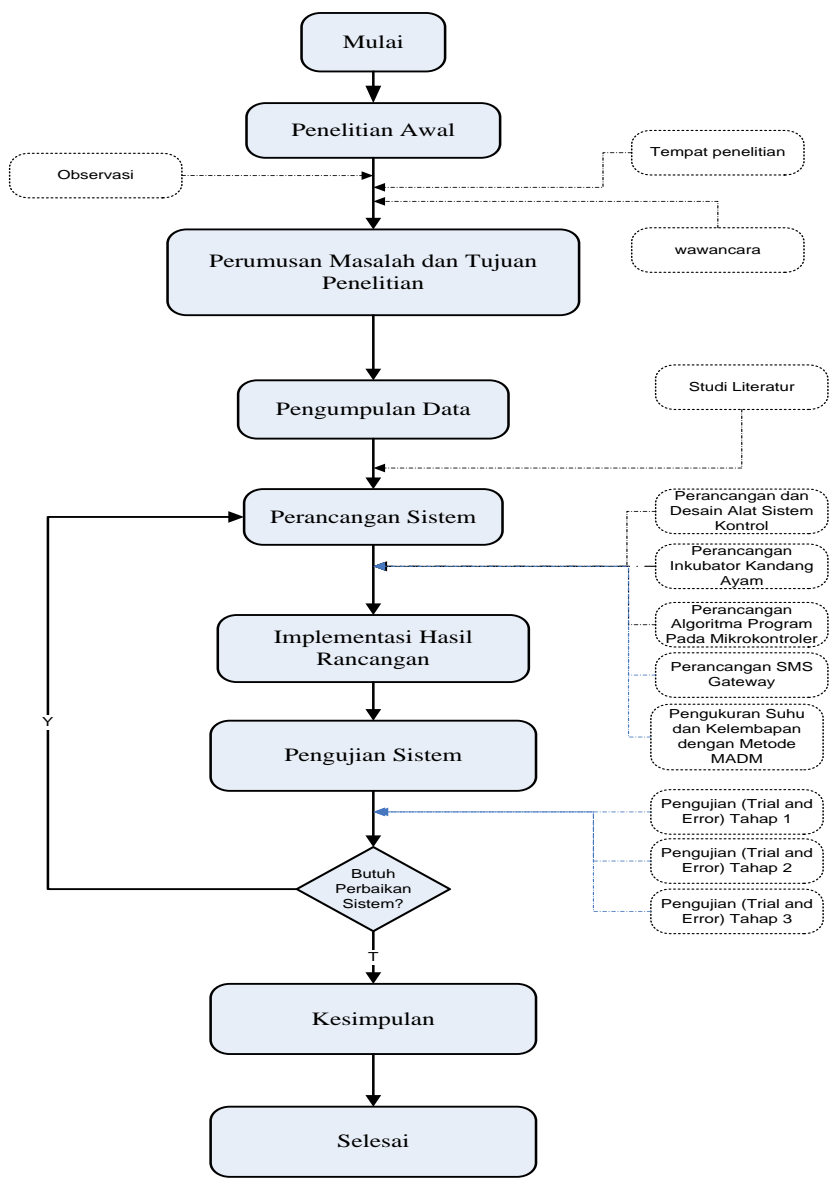

Gambar 1. Tahapan Penelitian

\section{A. Keterangan Tahapan Penelitian}

\section{Penelitian Awal}

Tahapan awal ini juga terdiri dari observasi tempat penelitian, kondisi dan situasi kandang ayam serta melakukan wawancara kepada peternak.

\section{Perumusan Masalah Dan Tujuan Penelitian}

Tahapan ini terdiri dari hasil wawancara dan obsevasi pada penelitian awal, ada beberapa permasalahan yang harus diselesaikan dengan sistem yang terorganisir dengan baik dan terencana. Proses Pengeraman telur ayam kampung, banyak nya benih telur mati akibat tidak adanya penghitungan suhu dan kelembapan dengan metode yang akurat, banyaknya induk ayam kampung tidak tahan cuaca sehingga banyak telur yang tidak bisa menetas

\section{Pengumpulan Data}

Tahapan pengumpulan data yaitu wawancara dan observasi pada penelitian awal, yang ditunjang dengan studi literatur. Studi literatur untuk mempelajari dan memahami cara mengeram induk ayam kampung, mikrokontroler Arduino Uno, SMS Gateway, Metode $M A D M$

\section{Perancangan Sistem}

Tahapan perancangan sistem terdiri dari memahami tentang sistem kontrol penetas telur ayam kampung menggunakan teknologi SMS Gateway dan Metode MADM. Tahapan ini terdiri dari perancangan dan desain alat sistem kontrol, perancangan inkubator kandang ayam, perancangan algoritma program pada mikrokontroler, perancangan sms gateway, pengukuran suhu dan kelembapan dengan metode MADM

\section{Implementasi Rancangan.}

Tahapan implementasi rancangan terdiri dari pengkodingan pada SMS Gateway dan Mikrokontroler Arduino Uno, yang sesuai dengan perancangan sistem.

\section{Pengujian Sistem}

Tahapan Pengujian Sistem ini yaitu menguji aplikasi dengan cara uji coba sistem. Jika sesuai maka dilanjutkan jika tidak maka kembali perancangan sistem. Tahapan eksperimen trial and error dilakukan sebanyak 3x. Tahapan pertama untuk memastikan telur ayam kampung menetas dengan sempurna dan memperhatikan konfigurasi sistem kontrol dan metode MADM. Tahapan kedua yaitu memastikan trial and error pada tahapan pertama terselesaikan dengan sangat baik sehingga telur ayam kampong menetas sempurna dan konfigurasi sistem kontrol dan metode MADM sebagai pengaturan suhu berjalan sangat baik. Tahapan ketiga yaitu pengujian sistem secara keseluruhan yang siap digunakan oleh peternak ayam kampung sehingga membantu menetaskan ayam kampung dengan sangat baik, efektif dan efisien.

\section{Penarikan Kesimpulan}

Tahapan ini adalah penarikan kesimpulan yang didapat dari sistem kontrol dan proses penelitian yang dilakukan dan tidak lanjut dari penelitian akan menjadi saran yang akan lebih dikembangkan lagi oleh penelitian berikutnya.

\section{B. Metode Simple Additive Weighting (SAW)}

Metode Simple Additive Weighting merupakan salah satu metode pendukung keputusan yang ada pada teknik Multi Attribute Decision Making (MADM). Metode SAW merupakan metode terbaik dalam penentuan keputusan[6][7]. Metode Simple Additive Weighting sering juga dikenal dengan istilah metode penjumlahan terbobot. Konsep dasar SAW adalah mencari penjumlahan terbobot dari kinerja setiap alternative pada semua atribut [5]. Metode SAW membutuhkan proses normalisasi matriks keputusan (X) ke suatu skala yang dapat dibandingkan dengan semua rating alternatif yang ada.

Dimana rij adalah rating kinerja ternormalisasi dari alternatif Ai pada atribut $\mathrm{Cj}: \mathrm{i}=1,2, \ldots, \mathrm{m}$ dan $\mathrm{j}=1,2, \ldots, \mathrm{n}$. Nilai preferensi untuk setiap alternative (Vi) diberikan sebagai berikut: Dimana $: r i j=$ rating kerja ternormalisasi. maxi= nilai maksimum 
dari setiap baris dan kolom. mini= nilai manimum dari setiap baris dan kolom. $X i j=$ baris dan kolom dari matriks. (rij) adalah rating kinerja ternormalisasi dari alternatif $(A i)$ pada atribut $(C j) \mathrm{i}=$ $1,2 \ldots, m$ dan $j=1,2 \ldots, n$. [5].

Pada penelitian ini terdiri dari beberapa dan kriteria dan alternatif. Hal ini menjadi salah satu terpenting dalam penentuan suhu dan kelembapan kandang ayam kampung. Kriteria dan alternatif sebagai berikut :

\section{a. Kriteria}

Bagian criteria merupakan salah satu bagian criteria menentukan suhu dan kelembapan. Berikut ini adalah Tabel 1. Kriteria Penentuan Suhu dan Kelembapan Kandang Ayam Kampung.

\section{TABEL 1. Kriteria Penentuan Suhu dan Kelembapan}

\begin{tabular}{|l|l|l|}
\hline No & \multicolumn{1}{|c|}{ Kriteria $(\mathbf{C})$} & \multicolumn{1}{c|}{ Nama Kriteria } \\
\hline 1. & Kriteria $(\mathrm{C} 1)$ & Intensitas Cahaya Lampu LED \\
\hline 2. & Kriteria $(\mathrm{C} 2)$ & Kelembapan Kandang \\
\hline 3. & Kriteria $(\mathrm{C} 3)$ & Ventilasi Ruang Kandang \\
\hline 4. & Kriteria $(\mathrm{C} 4)$ & Ukuran Ruang Kandang \\
\hline
\end{tabular}

\section{b. Alternatif}

Bagian alternatif merupakan bagian alternatif keputusan. Jika suhu dan kelembapan berada pada keputusan Alternatif 1 (A1) maka artinya $100 \%$ telur ayam kampung menetas, A2 maka 50\% telur menetas dan A3 maka 0\% telur gagal menetas. Berikut ini adalah Tabel 2. Alternatif Keputusan

TABEL 2. AltERNATIF KePUTUSAN

\begin{tabular}{|c|c|l|}
\hline No & Alternatif (A) & \multicolumn{1}{|c|}{ Nama Alternatif } \\
\hline 1. & Alternatif (A1) & $\begin{array}{l}\text { Suhu dan Kelembapan Kandang Sangat } \\
\text { Berhasil }\end{array}$ \\
\hline 2. & Alternatif (A2) & $\begin{array}{l}\text { Suhu dan Kelembapan Kandang Akan } \\
\text { Berhasil }\end{array}$ \\
\hline 3. & Alternatif (A3) & Suhu dan Kelembapan Kandang Gagal \\
\hline
\end{tabular}

\section{Metode SMS Gateway}

Short Message Service (SMS) akan memainkan peran yang sangat vital di area bisnis masa depan yang dikenal sebagai mobile banking, sistem pemasaran organisasi, dll. Untuk masa depan ini, SMS dapat membuat perangkat seluler dalam alat bisnis karena memiliki ketersediaan dan efektivitasnya. Tesis ini tentang pengembangan perangkat lunak yang didasarkan pada sistem layanan pesan singkat (SMS) untuk mengirim pesan melalui SMS gateway. Tujuan utama dari sistem yang diusulkan adalah untuk menyediakan otentikasi lokal multi-level ke layanan SMS gateway[8].

\section{HASIL DAN PEMBAHASAN}

\section{A. Hasil Penghitungan Penentuan Suhu dan Kelembapan Menggunakan Metode SAW}

Alur penghitungan metode Simple Additive Weigthing (SAW) yaitu menentukan bobot kriteria pada setiap alternatif, rating kecocokan dan bobot referensi. Selanjutnya hitung normalisasi terakhir yaitu perangkingan yang merupakan keputusan akhir.
Berikut ini alur penghitungan metode SAW untuk menentukan suhu dan kelambapan.

\section{Hasil Pembobotan Kriteria Pada Setiap Alternatif}

Tahapan ini adalah pembobotan criteria. Dibawah ini merupakan Tabel 3. Pembobotan Kriteria Pada Setiap Alternatif.

Tabel 3. Pembobotan Kriteria Pada Setiap Alternatif

\begin{tabular}{|c|c|c|c|c|c|}
\hline No & Alternatif & C1 & C2 & C3 & C4 \\
\hline 1. & A1 & 8 & 7 & 3 & 5 \\
\hline 2. & A2 & 4 & 4 & 5 & 4 \\
\hline 3. & A3 & 5 & 3 & 4 & 8 \\
\hline
\end{tabular}

2. Hasil Penghitungan Normalisasi Bobot Kriteria

Tahapan ini merupakan penghitungan normalisasi setiap kriteria pada setiap alternatif yg dapat dilihat pada Tabel 4 dibawah ini.

Tabel 4. NORMALISASI KRITERIA PADA SETIAP ALTERNATIF

\begin{tabular}{|c|c|c|}
\hline No & Alternatif/Kriteria & Nilai Normalisasi \\
\hline 1. & R11 & 0.8 \\
\hline 2. & R12 & 1 \\
\hline 3. & R13 & 0.8 \\
\hline 4. & R14 & 0.8 \\
\hline 5. & R21 & 0.8 \\
\hline 6. & R22 & 0.6 \\
\hline 7. & R23 & 1 \\
\hline 8. & R24 & 0.3 \\
\hline 9. & R31 & 0.3 \\
\hline 10. & R32 & 1 \\
\hline 11. & R33 & 0.8 \\
\hline 12. & R34 & 0.8 \\
\hline
\end{tabular}

Setelah melewati normalisasi maka selanjutnya pada tahap normalisasi matrik dan terakhir adalah perangkingan.

\section{Hasil Perangkingan}

Tahapan ini adalah perangkingan pada hasil normalisasi matrik dan nilai akhir pada algoritma SAW. Berikut ini hasil perangkingan.

$\mathrm{A} 1=(15)(0.8)+(13)(1)+(9)(0.8)+(8)(0.8)=38.6$

$\mathrm{A} 1=(15)(0.8)+(13)(0.6)+(9)(1)+(8)(0.3)=30.8$

$\mathrm{A} 1=(15)(0.3)+(13)(1)+(9)(0.8)+(8)(0.6)=29.5$

\section{B. Hasil Perancangan Sistem Kontrol Keseluruhan}

Bagian ini adalah hasil dari rancangan sistem kontrol penetas telur ayam kampung menggunakan metode MADM sebagai penentu suhu dan kelembapan, mikrokontroler sebagai sistem kontrol serta sms gateway sebagai media informasi pada peternak ayam.

\section{Karakteristik Kandang Ayam}

Kandang ayam untuk penetas telur yang telah dirancang dengan sistem kontrol suhu dan kelambapan memilik karateristik yaitu :

a. Kandang ayam berukuran panjang 2 meter dan 1 meter

b. Telur ayam yang dijadikan uji coba berjumlah 30 buah

c. Ventilasi kandang berjumlah 2 buah 
d. Lampu LED kapasitas 10 watt berjumlah 2 buah

e. Kandang ayam terbuat dari kayu triplek dengan ketebalan $9 \mathrm{~mm}$ dan dilapisi plastik supaya saat suhu lembab kayu tidak akan basah

f. Thermostat digital, sacral thermostat/bohlam dan saklar rak geser juga ada pada bagian depan kandang

g. Nampan air sebagai wadah air pada saat ruangan kandang lembab

h. Rak geser telur berfungsi untuk memutar telur pada hari ke 4 sampai ke 18. Rak akan bergeser selama 45menit dan interval pemutaran lagi setiap 3 jam. Pada hari ke 18 sampai ke 20 rak geser dihentikan karena hari ke 21 masuk fase telur ayam menetas

\section{Hasil Rancangan Sistem Kontrol pada Suhu $37.6^{\circ} \mathrm{C}$}

Tahapan ini merupakan sistem kontrol pada suhu $37.6^{\circ} \mathrm{C}$ dimana lampu LED akan hidup ecara otomatis berkat bantuan mikrokontroler artinya suhu pada ruangan kandang ayam mulai lembab. Lampu LED pada kandang berjumlah 2 buah masingmasing berkapasitas 10 watt. Hal ini dapat dilihat pada Gambar 1.

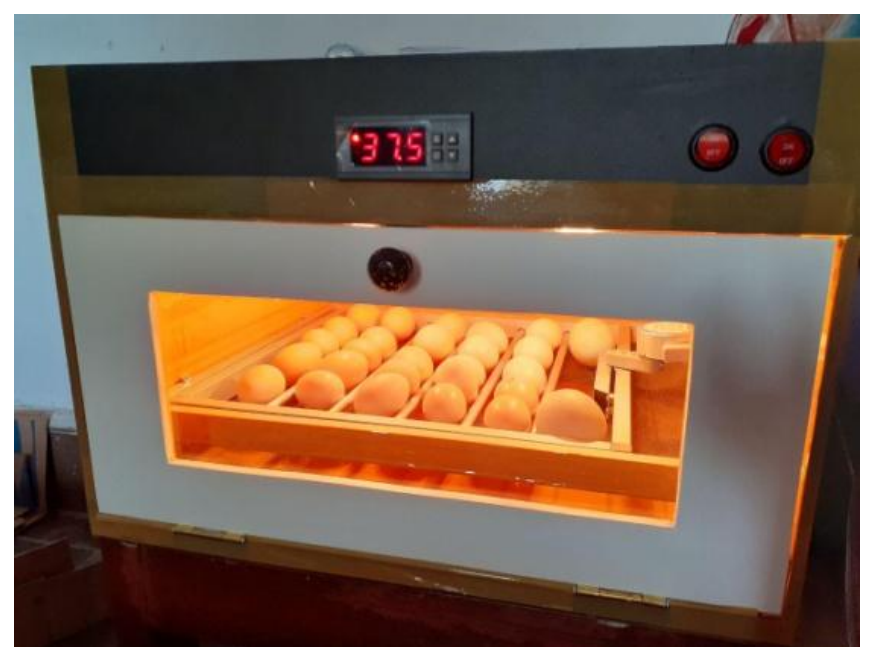

Gambar 1. Kandang Ayam Pada Suhu $37.6^{\circ} \mathrm{C}$

3. Hasil Rancangan Sistem Kontrol Pada Suhu $38^{\circ} \mathrm{C}$

Tahapan ini merupakan sistem kontrol pada suhu $38^{\circ} \mathrm{C}$ yang artinya lampu LED mati secara otomatis berkat bantuan dari mikrokontroler dan suhu didalam ruangan kandang ayam mulai panas. Hal ini dapat dilihat pada Gambar 2.

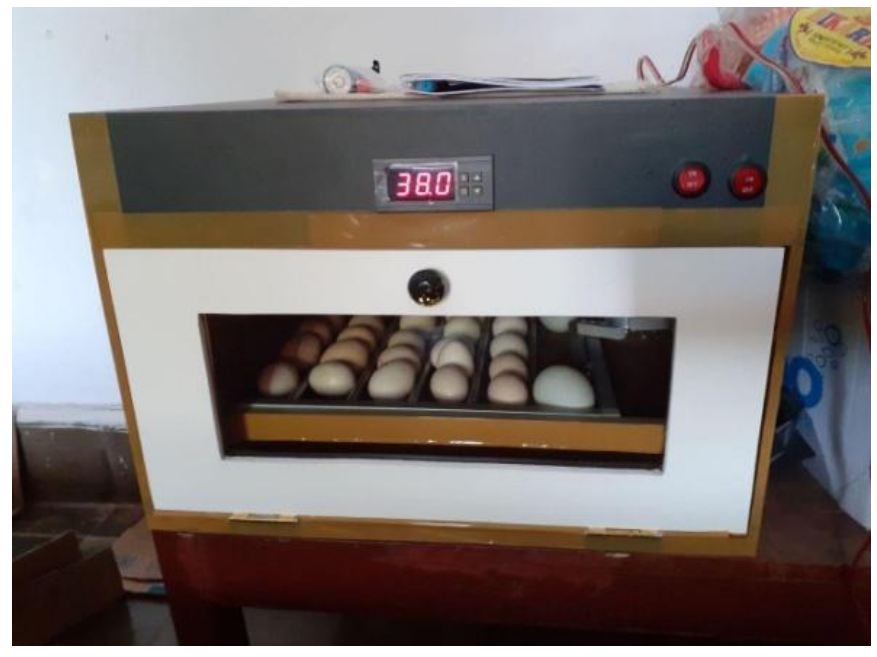

Gambar 2. Rancangan Sistem Kontrol Pada Suhu $38^{\circ} \mathrm{C}$

\section{KESIMPULAN}

Dari hasil perangkingan maka kesimpulannya terbukti kandang berada pada nilai A1 yaitu "suhu dan kelembapan kandang sangat berhasil" dimana ini menentukan tingkat keberhasilan menetasnya telur ayam dan suhu $38.6^{\circ} \mathrm{C}$ merupakan suhu paling sempurna untuk penetasan telur ayam. Sesuai waktu uji coba selama 21 hari terbukti $98 \%$ telur ayam dapat menetas semua dengan sempurna. Telur ayam yg digunakan berjumlah 50 butir telur.

Alat ini merupakan inovasi terbaru yang menggabungkan sistem kontrol mikrokontroler, sms gateway sebagai media informasi pada peternak bahwa penetasan telur berhasil dan metode Multi Attribute Decision Making (MADM) adalah metode yang tepat untuk menghitung bobot criteria pada setiap alternatif suhu dan kelembapan. Dan saran kedepan nya penggunaan sms gateway dapat dikembangkan menjadi berbasis Internet of Thing (IoT), metode MADM dapat dikembangkan menjadi MCDM atau DSS, sistem kontrol dapat digunakan untuk penetasan telur bebek atau burung puyuh.

\section{DAFTAR PUSTAKA}

[1] R. Agromedia, Beternak Ayam Kampung. Jakarta Selatan: PT. Agromedia Pustaka, 2007.

[2] S. Syafik, K. Joni, and A. F. Ibadillah, "Rancang Bangun Alat Penetas Telur Ayam Otomatis Dengan Metode Pid (Proportional Integral Derivative) Berbasis Energy Hybrid," J. Tek. Elektro dan Komput. TRIAC, vol. 4, no. 2, 2017.

[3] I. Larasati, N. Y. Dwi Setyaningsih, and M. Iqbal, "Rancang Bangun Sistem Kendali Suhu Pada Penetas Telur Ayam Berbasis Java Menggunakan Fuzzy Logic Control," Simetris J. Tek. Mesin, Elektro dan Ilmu Komput., vol. 10, no. 1, pp. 127134, 2019.

[4] S. P. Edy Ustomo, 99\% Gagal Beternak Ayam Petelur. 2016. 
[5] S. H. Sri Kusumadewi and R. W. Agus Harjoko, Fuzzy Multi-Attribute Decision Making (Fuzzy MADM). Yogyakarta: Graha Ilmu, 2006.

[6] S. H. Kusumadewi, "Fuzzy Multi-Attribute Decision Making (Fuzzy MADM)," Graha Ilmu Yogyakarta, p. 2006, 2006.

[7] J.-J. Huang, "Simple Additive Weighting Method," in Multiple Attribute Decision Making, 2011, pp. 55-67.

[8] V. Katankar and V. M. Thakare, "Short Message Service using SMS Gateway," Int. J. Comput. Sci. Eng., vol. 2, no. 4, pp. 1487-1491, 2010. 